\title{
Influence of Network Interaction Assessment on Regional Economy
}

\author{
Mariia A. Kamenskikh \\ Department of Economics and Management of Industry Production \\ Perm National Research Polytechnic University \\ Perm. Russia \\ permmak13@gmail.com
}

\begin{abstract}
Regions become more and more dependent on the level of innovations, because in recent years innovations have been developing as a resource of economic stability and growth. The region is an optimum platform for new knowledge commercialization. Thus, territories initiate the processes, which are connected with innovations. This article is devoted to the research of a question of the network interaction importance in the region in the context of economic and innovative development. The main attention is paid to research universities, enterprises and authorities' interactions, as these institutes are the main in the knowledge generation and commercialization processes through $R \& D$, financing, state programs, etc. Based on the theory of network regional interaction, creation of the theoretical and mathematical models, which are reflecting influence of network interaction on the level of economic development, seems possible. The research implies the analysis of factors of network interaction of universities, enterprises and authorities in the regional system.
\end{abstract}

Keywords - correlation, economy, region, authority, network

\section{INTRODUCTION}

Transformation of society to a post-industrial phase and knowledge economy, where technologies, knowledge, exchange of information play an essential role, inevitably affects development of the national states, influences forms of the public administration organization, business and society development, etc. In this context, researches of the changes happening at various levels of economy, identification tendencies and regularities of functioning and interaction between economic agents became more important. Emergence and development of new opportunities demand development and deployment of new methods because existing instruments cannot estimate changes.

Nowadays, the organization of main types of economic activity is connected with global scales. That is why one of the determining factors for behavior of various economic agents is using principles of network interaction.

According to M. Kastels's theory [15] about the modern world global processes and development of information technologies, revolution in information technologies is a starting point for analysing difficulties of formatting a new economy, society and culture. Changes in material technologies happen in parallel and along with changes in social and economic fields. Rigid and vertically focused institutes are replaced with lexible and horizontally focused networks. From this point of view, the theoretical approach, according to which the concept of the organization as an independent agent of market economy has to be replaced with the concept of emerging international networks of firms and institutes in a basic organizational form of information and global economy, is actual.

In view of the specified current trends of world economy development, which initiate generation functioning of a new type on the basis of the network concept, it is necessary to consider features of interaction of regional economy subjects in the context of network interaction, as well as the concept of knowledge economy.

In traditional understanding, the network is a set of the institutions with common goals, resources for their achievement and the uniform center for management. Networks are created in case of necessity of exchange resources for achieving the goal.

\section{LITERATURE REVIEW}

Many researchers state that innovations are a basis for a higher standard of population living and the main economic benefit. R. Atkinson [2] supposes that the competition level, market concentration, success of new knowledge commercialization and diffusion are provided as sources of innovative activity.

Regional networks reflect the level of the competition and market concentration. According to the OESD report, the network interaction is used in case of clusters formation as a method of regional innovative development, economic growth and global competitiveness in many regions.

In general, regional network is an agglomeration of the companies, suppliers, intermediaries, institutional organisations, which are connected through externalities and other effects and are concentrated in the area. E. Carayannis and V. Wang [5] assume that benefits of network interaction consist in specifics of an organizational structure, geographical uniformity and external effects, as well as features of the population, culture and technologies. 
Network interaction often realizes processes with central component knowledge. It can be characterized through joint $\mathrm{R} \& \mathrm{D}$, generation and commercialization of new knowledge and production of qualitatively new production. Knowledge as a resource becomes a subject of special interactions between participants of network.

Thus, the network is defined by interaction between independent subjects, which can be in different territories and have no connections to geographical restrictions (network structure), and by their internal communications (network processes). It is possible to allocate the network from an environment due to high intensity and long-term interaction; its participants have common goals which are achieved at the expense of combined and recombined resources. At the same time, each participant realizes one's own purposes. The network helps participants to get access to necessary information and to improve its using, knowledge generation and transfer.

There is a typology of the network organizations based on features of topological interrelations of subjects of the network [17]:

- closed (the number of network participants remains invariable within a limited number of iterations (no more than four) and production chains);

- $\quad$ opened (the number of network participants is limited by the territory);

- $\quad$ arachnoid (the number of participants is stable within key "knots" which provide stability of the network and involvement of new subjects).

The cluster-network collaboration is a new part of the network approach in the modern economy. It consists in reviewing of social and economic space as complex interacting territorial systems of transnational regions (territorial formations of national economy), including interaction among economic enterprises, authorities, administrative structures, the sector of non-profit organizations and social groups. At the same time, the most important component of interaction is the numerous cluster network communications, for example, between the same participants, and the participants, belonging to different levels of hierarchical systems. To understand regional and interregional network communications rationally, it is necessary to consider communication between the separate companies, non-governmental organizations, institutions of science and education, etc., and to analyze these correlations as a system of interregional interactions. Otherwise, an integral idea of network communications and their interference will not be created.

Cluster-network collaboration is regional specification, because resources (work forces, fixed assets, material support) and effects are concentrated on one territory. Cluster-network collaboration takes place owing to objectively existing need for voluntary combining. The network is created and retained by the general perspective and interests of all its members. Thus, the network is always a result of a project intention as participants shall participate in uniform goal-setting, coordinate mechanisms and diagrams of interaction, agree about results of activities.

It is possible to characterize cluster-network collaboration of the subjects of regional economy using certain features. Firstly, the current results of interaction of participants are in the form of growing fundamental knowledge and new knowledge generation. Secondly, the quality of specialized personnel resources and infrastructure is improving. Thirdly, low influence of geographical location allows interacting more actively. At last, cluster-network collaboration of subjects and the territory is developed. Non-effective cluster-network collaboration leads to insufficient interactions between education, business and public administration and, as a result, there is a lag in economic development of the region in comparison with the territories where cluster-network collaboration is implemented fully and a management system of this type of interaction exist.

The form of communications of cluster-network collaboration subjects of regional economy bears elements of self-organization and a joint involvement in control of activities. This type of interaction allows to solve a problem harmonization interests of different participants while networks are often created for obtaining competitive advantages and other private benefits.

Cluster-network collaboration of subjects of regional economy is a system of stable and long-term relations of subjects, which realize traditional roles and undertake functions of other participants of interaction. The science plays the main role; at the same time, interaction of participants leads to transformation of roles: universities become entrepreneurial, the enterprises pay more attention to scientific research and educational technologies, authorities undertake a role of venture fund and "manager" who supports cluster and network collaboration in general.

Each subject is in the process the solution of specific objectives of regional social and economic development, and as a result, planned strategic and tactical goals are achieved, results, and synergetic effect arise due to extending spheres of activities and transformation roles.

Network structures in the sphere of economy, production and the business networks, integrating different partners for providing additional economic benefits from cooperation of their participants. They play a significant role in creation of cluster-network collaboration. Cluster-network collaboration allows solving a problem of the spatial localization peculiar to a cluster. In other words, the considered type of interaction allows expanding a communication at the interregional level.

In the conditions of the increased deficiency of such resources as information, knowledge, competence and time, this form allows one to increase efficiency of the activity of its participants due to exchange between network participants. Associations of producers, Chambers of Commerce and Industry, etc. can be examples of such networks. This type of network structures can be characterized by the following definition: the network organizational structure is understood as an organizational type which is characterized by the freely related, flexible, horizontally organized structure of the 
network, which is essentially equal, equal by the roles and functions, independent partners in management.

The main opportunities of the network organization are:

- cooperation with the best partners;

- use of highly skilled labor (exception is its duplication);

- reduction and rational structure of expenses, growth of the income;

- organization of research with focus on the priority directions;

- flexibility, fast reaction to changes of subjects.

Network interaction of regional economy subjects is an open system, which attracts new participants due to overcoming closeness and autonomy of all network participants. Also it promotes strengthening of interaction by the principles of social partnership; forms of stable vertical and horizontal relations not only between subjects of regional economy, but also between groups of experts, etc.

Merging of institutes, which treat one or different types of activity at different stages of development, has features in the organization and management, allows one to create and develop networks and to reach effects of synergy in the following directions

- increase of efficiency of joint activity of network participants at the expense of knowledge, technologies, information and experience transfer;

- personnel, technological, strategic improvement and creation of new working groups;

- decrease of expenses with exception of the duplicating functions and creation of network structure;

- access to new resources such as knowledge, technologies, information, techniques and the ideas;

- increase of mobility and motivation, quality of work;

- development of a brand, the name of each participant of the network.

Institutional environment is environment in which network relationship is created and developed. This indicator is characterized by a set of parameters: the financial market level of development, market of personnel and intellectual capital, commodity market, the corporate structure, state regulation, the legislation mechanism. Often predisposition of an institutional environment to network formation depends on the trust degree between institutes.

Environment, where the level of credibility is high, does not need various contract guarantees, and has simple controlling and limiting mechanisms for management. The low level of credibility results in impossibility of cooperation.

Increasing trust between network participants is possible due to strengthening of vertical and horizontal integration using joint property or production of joint product. These operations make it possible to use controlling, restrictive and coordinating mechanisms and sufficient extent of management. It is possible in the network interaction of regional economy subjects to carry out implementation of joint projects, which are financed from the state.

Development of network organizational forms has created the new type of economy which is characterized by the concept "network economy". Other definitions are also used along with the concept "network economy": information economy, economy of direct equal connections. The network economy makes basis of modern information society and is based on the fifth technological way, in which the leading positions are occupied by computer and information technologies, space communication. The global information network is a necessary condition of its existence. The network economy promotes globalization finance, goods, labor markets. In the conditions of network economy, network interaction gains ground due to openness of systems, simplification of processes of information exchange, knowledge and technologies transfer and an increase in intensity of interrelations.

Some authors understand the state of the economy as the term "network economy", when the serving functioning infrastructure (for one country or group of the countries) is based on using IT-technologies. At the same time, the economic system in general and its separate elements change (there are network forms of the organization and the mechanism of coordination, changes in market institutes, etc.) The term "network economy" is the most widespread in scientific literature; however, according to a number of authors, it is not absolutely exact. In strict understanding of terms, any economy is network since it is based on networks of communications among their participants. In the conditions of network economy, there is an intensive replacement of "heavy and material" substances and "easy and information" with an intensive growth of "an intellectual component" of the made production. Interaction of regional economy subjects within the concept of network economy gains crucial importance because network interaction allows one to carry out new knowledge generation and commercialization more quickly and productively.

Emergence of additional properties of the network as systems is explained by the synergetic effect concept. The effect of synergy implies the result, obtained from joint use of objects or resources (material, energy and information), which exceeds the amount of results, gained from using the same resources separately. In general, the synergetic effect is perceived as the joint, unidirectional, approved activity, mutual use of resources (information, technological, human) of network participants that leads to multiplication effect or strengthening of system effectiveness.

Synergetic effect is a basic characteristic effect of selfdevelopment for economic systems. Thus, networks receive a better result with the help of stronger interaction, and the effect of self-development is traditionally called synergy.

The basic component of regional economic development is network interaction, especially among universities, enterprises 
and authorities. This thesis is reflected in the Triple Helix model of G. Etzkowitz [9] The Triple Helix model is determined by the key role of university in knowledge generation and regional development with iteraction of three main participants - universities, enterprises and authorities. C. Christensen and R.Rosenbloom [6] confirm the importance of network interaction. According to their work, territorial interrelations are the basis for innovative development. In general, regional networks represent the dynamic system, which aim is generation of innovations. The main objective of the regional system is economic development and increasing competitiveness. Network interaction includes the following components [16]: organization of a technological transfer; R\&D financing; joint projects; general information systems.

This classification reflects interaction of industrial enterprises with other institutes in the sphere of transfer technologies. P. Cooke [7] describes critical characteristics of regional networks: generation of new fundamental and applied knowledge; venture capital funds; availability of territorial interrelations.

The literature analysis devoted to problems of regional development allows one to draw a conclusion that network interaction subjects of regional economy exert the considerable impact on new knowledge generation and commercialization. The important part in this interaction is assigned to universities as the sources of new knowledge promoting its creation, distribution and application in many fields of activity.

The factors, characterizing conditions of network interaction implementation, were defined. In case of network analysis, it is necessary to consider fundamental factors and system elements of development, control at the national and regional levels:

- complex of the economic, legal, organizational and administrative, implementation factors determining development in the network;

- system control of the network at national (federal), regional (territorial) and local (local) levels;

- technical and human potential of the territory as a driving factor of economic development;

- elements reflecting interaction and their economic correlations;

- elements reflecting tools or mechanisms acceptance of the administrative decisions managing network

Various types of regional networks represent a set of institutes and interrelation, as well as additional effects, externalities or synergetic effect. T. Campbell [3] describes developing more competitive regions with effective networks of knowledge. Information, training and creativity are accepted as a part of information regional infrastructure in networks. In his work, the hypothesis about the transfer of knowledge and information infrastructure is a regional competitiveness basis. In general, the purpose of network interaction of universities and enterprises is provided in figure 1.

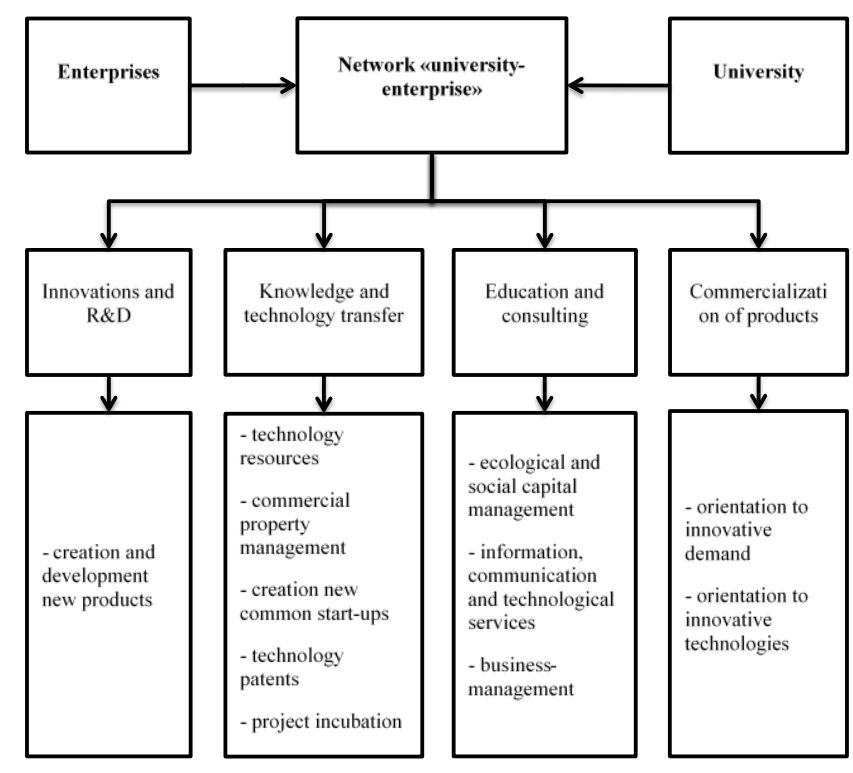

Fig. 1. Network interaction of universities and enterprises [14]

In general, the network can be determined as a form, decentralized complex of the interconnected nodes of open type, which are capable of extending by inclusion of new links (structures, associations, organizations), which imparts flexibility and dynamism to this form. To be a node of the network means to have own author's content about general perspective of the network, to have own resources and infrastructure for implementation of the content, to understand that this content partially and to purchase additional resources with the help of other institutions [20].

These theories are based on several major factors of network interaction between universities and enterprises, which promote regional innovative and economic development. In other works, science and technology parks and technopolices, "the studying territories", regional innovative systems, the creative cities join universities, enterprises and authorities interaction. Research shows [1, 13, 19] that in developed countries, network interaction is based on the initiative of participants. In developing countries, there is a stimulation of network interaction "from above" with the help of the state projects and regulatory legal acts.

At the moment, there is a huge amount of the works, which are describing the existing regional networks from the theoretical point of view, but quantitative measurement of interrelations has not been taken yet. But there are measurable models of separate parts of the regional network. For example, E. Rogers [18] researches mechanisms of a technological transfer between research laboratories and industrial enterprises in Japan and Germany. The main conclusion of the work is detection of dependence between the level of a technological transfer and commercialization of innovations. E. Carayannis [4] makes attempt to classify various types of regional networks on the basis of the innovative development level, allocating critical elements of interaction and the main participants. 
M. Yu. Sheresheva [19] suggests that the level of economic development can be reflected through the amount of the new organizations. The growing quantity of firms, especially small innovative enterprises, promotes activization of universities technological transfer. S. Hackett and D. Dilts [11] research confirms positive influence of universities' $R \& D$ financing and activities on the number of new firms. Also the number of the new organizations promotes regional economic and innovative development. Other work is devoted to interaction of universities and enterprises and their influence on the number of new firms. Z. Griliches [10] specifies close interrelation of granted patents number and $R \& D$ financing.

Many researchers confirm positive communication of expenses on R\&D and economic development of the territories. Increasing costs of enterprises for research raise probability of more intensive development of innovations through generation of new knowledge. The second indicator in the group can exert impact on regional economic development through creation of human capital. Graduates of universities become a part of human capital and high-skilled labor force. Regions with a huge amount of university graduates have more intensive entrepreneurial activity. Post-graduate students, in turn, can become a peculiar conductor between universities and enterprises and strengthen a transfer of the ideas.

\section{DATA AND ESTIMATION TECHNIQUES}

According to the analyzed literature about influence of network interaction between universities and enterprises depending on regional economic development, independent and control variables are revealed. The level of unemployment, the amount of new firms are determined as dependent variables GRP per capita.
The basic and most important measuring instrument of regional economic development is GRP per capita. This indicator is often used in the research devoted to quality of life, the level of economic development. The following indicator is unemployment. The high level of unemployment reflects negative tendencies in regional economy. The third indicator in the group of dependent variables is the amount of new firms.

Internal costs for R\&D from the organizations, the amount of graduates and post-graduate students of universities belong to independent variables. For the purposes of determining the influence of network interaction, it is necessary to allocate the factors, which are characterizing interrelations between universities and the enterprises. Financing of $R \& D$ in regions, first of all, belongs to such indicators.

The number of patents, employed in the economy, crime rate, the rate of the population growth, the number of enterprises, population are taken as control variables. These indicators are chosen on the basis of the existing researches; they are indirectly connected with network interaction and exert impact on regional economic development. One of the important control variables is the number of patents, which are granted in regions. In many works, patents are described as the measuring instrument of the innovative development level of the territory.

The level of regional economic development can be determined through quality of life. This indicator is measured through the crime rate and change of population. Many studies confirm outflow of the population from regions with a large number of crimes. Indicators of population reflect general appeal of the region, positive dynamics directly influences economic development of the territory.

TABLE I. CORRELATION INDICATORS OF NETWORK INTERACTION AND INDICATORS OF REGIONAL ECONOMY

\begin{tabular}{|c|c|c|c|c|c|c|c|c|c|c|c|}
\hline & $\begin{array}{c}\text { GRP } \\
\text { per } \\
\text { capita, } \\
\text { thous. } \\
\text { rub. }\end{array}$ & $\begin{array}{c}\text { Unempl } \\
\text { oyment } \\
\text { rate }\end{array}$ & $\begin{array}{c}\text { New } \\
\text { firms, } \\
\text { ea. }\end{array}$ & $\begin{array}{c}\text { R\&D } \\
\text { expenses, } \\
\text { mln. rub. }\end{array}$ & $\begin{array}{l}\text { Graduates } \\
\text { and post- } \\
\text { graduates, } \\
\text { ppl. }\end{array}$ & $\begin{array}{l}\text { Granted } \\
\text { patents, } \\
\text { ea. }\end{array}$ & $\begin{array}{l}\text { Amount } \\
\text { employed } \\
\text { in the } \\
\text { economy, } \\
\text { k. ppl. }\end{array}$ & $\begin{array}{l}\text { Criminal } \\
\text { rate, ea. } \\
\text { per } 1000 \\
\text { ppl. }\end{array}$ & $\begin{array}{l}\text { Population } \\
\text { growth } \\
\text { rate }\end{array}$ & $\begin{array}{c}\text { Amount of } \\
\text { enterprises, } \\
\text { ea. }\end{array}$ & $\begin{array}{l}\text { Population, } \\
\text { thous. ppl. }\end{array}$ \\
\hline $\begin{array}{l}\text { GRP per capita, } \\
\text { thous. rub. }\end{array}$ & 1.00 & & & & & & & & & & \\
\hline $\begin{array}{l}\text { Unemployment } \\
\text { rate }\end{array}$ & -0.36 & 1.00 & & & & & & & & & \\
\hline New firms, ea. & 0.17 & -0.46 & 1.00 & & & & & & & & \\
\hline $\begin{array}{l}\text { R\&D expenses, } \\
\text { mln. rub. }\end{array}$ & 0.54 & -0.46 & 0.65 & 1.00 & & & & & & & \\
\hline $\begin{array}{l}\text { Graduates and } \\
\text { post-graduates, } \\
\text { ppl }\end{array}$ & 0.63 & -0.46 & 0.80 & 0.91 & 1.00 & & & & & & \\
\hline $\begin{array}{l}\text { Granted patents, } \\
\text { ea. }\end{array}$ & 0.35 & -0.43 & 0.55 & 0.95 & 0.95 & 1.00 & & & & & \\
\hline $\begin{array}{l}\text { Amount employed } \\
\text { in the economy, } \\
\text { thous. ppl. }\end{array}$ & 0.11 & -0.44 & 0.94 & 0.48 & 0.64 & 0.48 & 1.00 & & & & \\
\hline $\begin{array}{l}\text { Criminal rate, ea. } \\
\text { per } 1000 \text { ppl. }\end{array}$ & 0.10 & 0.17 & -0.04 & -0.05 & -0.08 & -0.06 & -0.15 & 1.00 & & & \\
\hline $\begin{array}{l}\text { Population growth } \\
\text { rate }\end{array}$ & 0.12 & 0.08 & 0.28 & 0.42 & 0.46 & 0.41 & 0.33 & -0.18 & 1.00 & & \\
\hline $\begin{array}{l}\text { Amount of } \\
\text { enterprises, ea. }\end{array}$ & 0.21 & -0.52 & 0.98 & 0.59 & 0.73 & 0.59 & 0.96 & -0.11 & 0.31 & 1.00 & \\
\hline Population, k. ppl. & 0.05 & -0.34 & 0.93 & 0.46 & 0.63 & 0.47 & 0.99 & -0.14 & 0.38 & 0.94 & 1.00 \\
\hline
\end{tabular}


The analysis was carried out on the basis of indicators of all Russians regions for 2013-2014 according to statistical data.

\section{EMPIRICAL RESULTS}

Results of the correlation are displayed in table 1 . Influence of indicators is reflected in the range from +1 to -1 . The positive value reflects direct influence; the negative - a reverse one. The indicator exceeding the value by $+/-0.6$ is considered significant.The correlation matrix partially confirms a hypothesis about positive influence of universities and the enterprises network interaction by regional economic development. Significant influence of the number of graduates and post-graduate students on GRP and the amount of new firms is revealed. $R \& D$ expenses influence the amount of new firms; at the same time, correlation with GRP is not so strong. Any of independent indicators does not exert critical impact on unemployment rate. At the same time, inverse relation of R\&D expenses, the number of graduates and post-graduate students and unemployment rate is obvious.

The determination coefficient for an indicator of GRP is per capita and equal to 0.38 . Thus, the number of graduates and post-graduate students, $\mathrm{R} \& \mathrm{D}$ expenses exerts stronger impact on GRP than other factors. Determination coefficients for unemployment rate and the number of the new firms are equal 0.81 and 0.98 , respectively, that allows drawing a conclusion on the low level of influence of the number of graduates and post-graduate students, $R \& D$ expenses in comparison with other factors.

\section{CONCLUDING REMARKS}

In general, it is possible to draw a conclusion about expediency of strengthening network interaction of universities, enterprises and authorities for regional economic and innovative development. For a further research, extension of the list of the indicators, reflecting network interaction and its influence on region economy, seems possible.

The analysis of the existing methods of assessment of universities, enterprises and authorities interaction shows that there is no method of estimating the new tendencies and interrelations, appearing in global changes and transition to knowledge economy. For this reason, the author's technique of assessment of universities and enterprises network interaction, influencing the region economy on the basis of the system of regional factors, is developed. This model is calculated by the example of Perm Krai.

It is possible to develop a research in the direction of carrying out the interregional analysis for construction and measurement of network interactions and development of recommendations for different regions.

\section{References}

[1] S.I. Ashmarina, E. A. Kandrashina, “ Concepts of interactions between universities and enterprises in framework realisation of international projects". Samara State University of Economics Report, vol. 81, pp. 59, 2011.

[2] R. Atkinson, D. Castro, "A national technology agenda for the new administration". Yale Journal of Law and Technology, vol. 11, pp. 190208, 2009.

[3] T. Campbell, Learning cities: converting discovery to knowledge in complex systems, San Rafael: Urban Age Institute, 2009, pp. 41-44.

[4] E. Carayannis, "Knowledge-driven creative destruction, or leveraging knowledge for competitive advantage". Independent Higher Education, vol. 22, pp. 343-353, 2008.

[5] E. Carayannis, V. Wang, The role of the firm in innovation networks and knowledge clusters. Innovation networks and knowledge clusters, Palgrave New York: MacMillan, 2008, pp. 28-29.

[6] C. Christensen, R. Rosenbloom, “ Explaining the attacker's advantage: technological paradigms, organizational dynamics, and the value network". Research Policy, vol. 24, pp. 233-257, 1993.

[7] P. Cooke, "Economic globalization and its future challenges for regional development". Technology Management, vol. 26, pp. 401-420, 2003.

[8] I. G. Dezhina, V. V. Kiseleva, State, science and business in innovative system in Russia, Moscow: IEPP, 2008, pp. 85-86.

[9] J. Dzisah, H. Etzkowitz, The Age of Knowledge Studies in Critical Social Sciences, Oxford: Oxford University Press, 1990, pp. 34-35.

[10] Z. Griliches, "Patent statistics as economic indicators: a survey". Journal of Economic Literature, vol. 28, pp. 1661-1707, 2002.

[11] S. Hackett, D. Dilts, "A systematic review of business incubation research". Journal of Technology Transfer, vol. 29(1), pp. 55-82, 2004.

[12] O. V. Inshakov, "Collaboration as global form organisation knowledge economy”. Regional Economy, vol. 3, pp. 38-45, 2013.

[13] M. A. Kamenskikh, "Research of creative industries concept and estimation their influence on economic development in Russia". Economic Analysis: Theory and Practice, vol. 8 (359), pp. 62-68, 2014.

[14] M.A. Kamenskikh, "Research of universities influence on regional economic development". Regional Economy: theory and practice, vol. 42 (369), pp. 12-20, 2014.

[15] M. Kastels, The Information age: economy, sosiety and culture, Oxford: Blackwell, 2000, pp. 12-16.

[16] N. Komninos, "Regional intelligence: distributed localized information systems for innovation and development". Technology Management, 2002, vol. 28, pp. 483-506.

[17] Zh. Mingaleva, I. Mirskikh, "On innovation and knowledge economy in Russia", World Academy of Science. Engineering and vol. 66, pp. 1032-1041 Technology, 2010.

[18] E. Rogers, Diffusion of innovationsm, New York: Free Press, 2002, pp. 68.

[19] M. Yu. Sheresheva, Forms of firms network interactions, Moscow: HSE publishing house, 2010. pp. 95-97.

[20] E. V. Vasilevskaja, Network organisation as new type relations and activities in modern conditions, Moscow: APKPPRO, 2007, pp. 55-58. 